\title{
Pulmonary thrombo-endarterectomy for chronic thromboembolic pulmonary artery hypertension
}

\author{
Sofia Martin-Suarez ${ }^{1}$, Gregorio Gliozzi ${ }^{1}$, Antonio Loforte ${ }^{1}$, Fabio Niro ${ }^{2}$, Mariafrancesca Fiorentino ${ }^{1}$, \\ Giulio Giovanni Cavalli ${ }^{1}$, Massimiliano Palazzini ${ }^{3}$, Francesco Saia ${ }^{3}$, Niccolò Barbera ${ }^{4}$, Marco La Monaca ${ }^{5}$, \\ Nazzareno Galiè ${ }^{3}$, Davide Pacini ${ }^{1}$
}

${ }^{1}$ Cardiac Surgery Unit, Cardio Thoracic and Vascular Department, Bologna University, Bologna, Italy; ${ }^{2}$ Interventional Radiology Unit, Cardio Thoracic and Vascular Department, Bologna University, Bologna, Italy; ${ }^{3}$ Cardiology Unit, Cardio Thoracic and Vascular Department, Bologna University, Bologna, Italy; ${ }^{4}$ CardioThoracic Anaesthesia Unit, Cardio Thoracic and Vascular Department, Bologna University, Bologna, Italy; ${ }^{5}$ Clinical Perfusionist, Cardio Thoracic and Vascular Department, Bologna University, Bologna, Italy

Contributions: (I) Conception and design: S Martin-Suarez, D Pacini; (II) Administrative support: None; (III) Provision of study materials or patients: G Gliozzi, S Martin-Suarez; (IV) Collection and assembly of data: S Martin-Suarez, G Gliozzi, GG Cavalli; (V) Data analysis and interpretation: S Martin-Suarez, G Gliozzi; (VI) Manuscript writing: All authors; (VII) Final approval of manuscript: All authors.

Correspondence to: Sofia Martin-Suarez, MD, PhD. Cardiac Surgery Unit, Cardio Thoracic and Vascular Department, Bologna University, S.Orsola Hospital, Pad 23 POLO CTV, Via Massarenti 9, 40138, Bologna, Italy. Email: docsofi74@hotmail.com; sofia.martinsuarez@aosp.bo.it.

Background: Chronic thromboembolic pulmonary hypertension (CTEPH) is the only type of pulmonary hypertension $(\mathrm{PH})$ with a surgical treatment aimed to remove fibrotic thrombus allowing a significant lowering of pulmonary vascular resistances (PVR) or even normalisation of PH. Pulmonary thromboendarterectomy (PTE) is performed through full median sternotomy, cardiopulmonary bypass (CPB) with periods of deep hypothermic circulatory arrest (DHCA). Diagnostic process, patient selection, surgical and postoperative management require specific expertise and a multidisciplinary team as we have in our department. In the present paper we will expose our single-center 17-year retrospective experience on PTE. Methods: We present a cohort of 177 consecutive PTE patients underwent surgery in two different "Eras": groups 1 and 2, with 96 and 81 patients respectively. During the first period (2003 to 2012) DHCA was applied strictly if venous pulmonary back-bleeding precluded a complete endarterectomy, while during the second era [2012-2020] DHCA was routinely adopted during CPB. Retrospective analysis of preoperative data, as well as surgical characteristics and postoperative outcome have been compared between groups.

Results: Some differences on preoperative clinical and hemodynamic data have been found, as the incidence of concomitant chronic pulmonary disease and more decompensated profile in the first group. On the other hand, in group 2, a larger number of patients were preoperatively treated with specific pulmonary vasodilators. Cross clamp time as well as time of CPB were significantly shorter in group 2 in spite of a mean DHCA time of 33 minutes. In-hospital mortality was $15.6 \%$ and $3.7 \%$, in groups 1 and 2 respectively. Pulmonary hemodynamic as well as long term outcome equally and significantly improved in both groups.

Conclusions: Our experience demonstrates that, as in other fields of cardio-thoracic surgery, learning curve strongly impact on results: multidisciplinary preoperative evaluation and selection of patients, surgical planning and well-defined intra- and post-operative protocols contribute to improve hemodinamics and clinical outcomes. This assertion acquires more sense since this pathology is considered a rare one, requiring deep knowledge on its pathophysiology, diagnostic procedures, therapeutic alternatives, as well as specific skills on surgical and anaesthetic management. Our CTEPH center offers all the needed pathway, from diagnostic to therapeutic alternatives, with excellent results.

Keywords: Pulmonary hypertension (PH); thromboembolic; endarterectomy; deep hypothermic circulatory arrest

Received: 06 August 2020; Accepted: 16 December 2020; Published: 25 May 2021.

doi: $10.21037 /$ ccts-20-137

View this article at: http://dx.doi.org/10.21037/ccts-20-137 


\section{Introduction}

Chronic thromboembolic pulmonary hypertension $(\mathrm{CTEPH})$ is defined as an increase of mean pulmonary artery pressure $(\mathrm{PAPm})$ over $25 \mathrm{mmHg}$ associated with defects of pulmonary arteries patency, after at least 3 months of full and efficient anticoagulation. CTEPH is a long term consequence of an unsolved or not recognised acute pulmonary embolism and, if untreated, has a poor prognosis. Clots turn fibrotic and strongly adhere to the arterial walls, narrowing or occluding the lumen at different levels. CTEPH is a rare disease, with a tricky differential diagnosis. A clinical history of previous acute pulmonary embolism is not always present and it is estimated that less than $40 \%$ of patients have an episode of acute pulmonary embolism (1). Clinical presentation includes many unspecific symptoms, such as progressive exertional dyspnea, palpitations, hemoptysis, syncope and venous congestion. Patients show various hemodynamic profiles and different degrees of pulmonary hypertension $(\mathrm{PH})$, not always proportional to the extent of pulmonary arteries occlusion: in fact, in the small arteries not involved by chronic pulmonary embolism, the overflow is at first associated to vasoconstriction and then to a progressive structural remodeling with wall hypertrophy, increasing pulmonary vascular resistances (PVR) progressively $(2,3)$. Additionally, there are asymptomatic patients with chronic thromboembolic pulmonary lesions without $\mathrm{PH}$, representing another controversial pathological entity, the so-called chronic thromboembolic disease (CTED). CTEPH is the only kind of $\mathrm{PH}$ with a potentially curative surgical treatment different from lung transplantation: the pulmonary thrombo-endarterectomy (PTE). However, operability assessment is a complex process, made by a multidisciplinary and dedicated team, including pulmonologists, cardiologists, radiologists and surgeons. Possibly, the most important factor in determining surgical feasibility is the correlation of severity of $\mathrm{PH}$ versus the extent of the obstruction. Individual patient factors, including comorbidity and the level of expectations for longterm benefits, are crucial in the decision-making process. PTE operation requires a team of dedicated and trained surgeons as well as critical care expert physicians in the postoperative period. As a general rule, PTE follows four basic principles: (I) the endarterectomy must be bilateral, therefore anterior approach through median sternotomy is mandatory; (II) a clear surgical field is essential: this is obtained through deep hypothermic (at $20{ }^{\circ} \mathrm{C}$ ) cardiopulmonary bypass $(\mathrm{CPB})$ associated with periods of circulatory arrest; (III) identification of the correct dissection plane is crucial to reduce vascular resistances as much as possible; (IV) a complete endarterectomy reaching sub-segmental arteries is essential (4).

PTE surgeons should carefully evaluate preoperative anatomy in order to forecast if a complete endarterectomy is practicable: only few patients show distal lesions beyond segmental arteries. Although distal anatomy it is not an absolute contraindication to surgery (it only makes harder the surgical dissection, with longer surgical times), CTEPH teams could now offer an alternative therapeutic option: in inoperable patients or in patients with recurrent/persistent PH after PTE, the balloon pulmonary angioplasty (BPA) is a good second choice.

The CTEPH complex diagnosis, its epidemiology, the heterogeneous clinical expressions and the different therapeutic options, are the main reasons that justify that only dedicated and expert CTEPH centers must take care of these patients, being few in every country. Ours is one of the two dedicate centers in Italy, and the only one able to offer the entire therapeutic diagnostic path to the patient affected by CTEPH.

In the present paper we will expose our 17 years of experience on PTE.

We present the following article in accordance with the STROBE reporting checklist (available at https://ccts. amegroups.com/article/view/10.21037/ccts-20-137/rc).

\section{Methods}

From 2003 to 2020, we performed 177 PTE. Our center is a national referral center for $\mathrm{PH}$. CTEPH patient represents $30 \%$ of all referred $\mathrm{PH}$ patients with a prevalence of nearly 40 cases per million of inhabitants. Some of this patients are referred to our center with the CTEPH diagnosis already made. Many patients reach our center with unspecific $\mathrm{PH}$ diagnosis, mostly because very distal and imperceptible disease, and CTEPH diagnosis is made by us. As expert center, we complete diagnosis and assessment in order to offer the patient the best therapeutic solution. Every single case of CTEPH is formally discussed in the multidisciplinary meeting, where pulmonary angioTC scan, angiography, catheterisation, echocardiography are deeply analysed. PTE, BPA or medication are the three therapeutic options, being PTE the first choice. BPA or medical therapy are intended for patients considered not good 

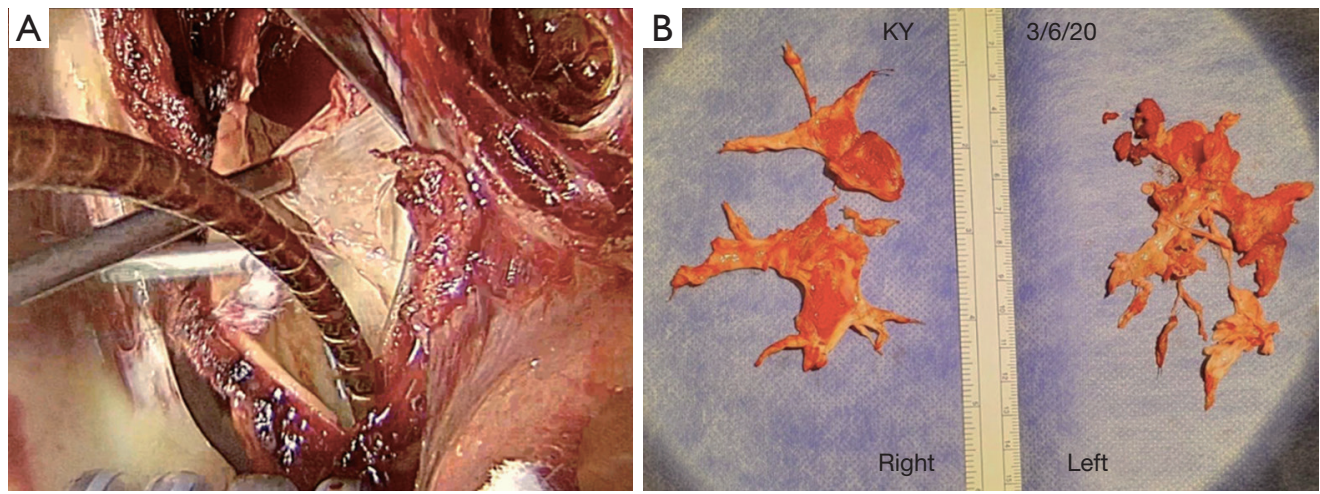

Figure 1 Intraoperative pictures of a PTE operation. (A) Recognition of cleavage plane; (B) surgical specimen. PTE, pulmonary thromboendarterectomy.

candidates to surgery, depending on anatomy, hemodynamic and comorbidities. Operation is made through median sternotomy. After pericardiotomy, CPB is started with a cannula in the ascending aorta and two venous cannulae in the cava, the superior one positioned directly from the right atrial appendage to avoid right pulmonary exposure obstacle. Also the main pulmonary artery and the left ventricle are drained. Once the CPB begins, the systemic cooling proceeds progressively, maintaining a minimum thermal gradient. While cooling, myocardial protection and aortic cross clamping (ACC) are achieved. In our center we use crystalloid Custodiol Solution (5). At the beginning of our experience, we entered into a protocol aimed to avoid deep hypothermic circulatory arrest (DHCA). At 25 degrees of core temperature, pump flow could be lowered until even less than one liter per minute, while maintaining good perfusion parameters in particularly the mixed venous oxygen saturation $(>65 \%)$. At a very low pump flows, the back flow can be as scarce as in arrest, allowing a complete endarterectomy. The main disadvantage of this method and in an unpredictable manner (perhaps the extent of collateral bronchial circle could serve as an indicator) in spite of a minimum pump flow, the retrograde flow is making it impossible to impose endarterectomy $(6,7)$. This constrains to go back to pump full flow to reach 20 degrees of temperature and proceed with the DHCA, prolonging in these cases the extracorporeal circulation $(\mathrm{CPB})$ and aortic cross-clamping times. That's why since 2012 until now and to stay in line with the greatest experts in PTE, we have decided to directly adopt deep hypothermia at 20 degrees with periods of 20 minutes of circulatory arrest interspersed with 10 minutes of isothermal reperfusion if procedure prolongs. Other authors have demonstrated any advantage by adopting different methods than DHCA (8). Right and longitudinal arteriotomy is performed, and cleavage plane identified. Progressively the fibrotic thrombus is detached from the wall and pulled back until the very distal branches (Figure 1). After the right endarterectomy is concluded and the artery reconstructed, the PTE in the left side is performed in the same fashion. Once bilateral PTE is completed, the patient is progressively rewarmed until normothermia. If associated procedures are indicated, like coronary bypass, those are performed during the rewarming period. Then CPB is stopped and hemostasis and wound closure done in the usual way. During and after the operation, management of water balance, electrolyte control, cardiac output as well as peripheral systemic resistance, and anticoagulation are some of the fundamental aspects that require very delicate adjustments, being a topic worthy to be deeply detailed in another paper.

Patients were followed up at 3, 6, and 12 months and then yearly with echocardiogram, and 6-minute walk distance (6MWD). Right heart catheterization was performed when patients experienced deterioration in New York Heart Association (NYHA) Functional Class, remained in Class III after PEA, or presented with persistent deterioration in the 6MWD in the presence of residual $\mathrm{PH}$ on echocardiogram.

Our cardiovascular surgery center of Sant'Orsola Hospital in Bologna (Italy) was born in 1974, being an Italian and European reference in aortic surgery and cardiac transplantation. Thanks to our huge experience in those two fields and also to the close collaboration with Prof. N. Galié, world's leading expert in PH, in 2003 we established the PTE program, after learning from experts like Prof. Jamieson from San Diego. We have performed 177 PTE in 174 patients in 17 years (three patients underwent PTE reoperation because of CTEPH recurrence, mainly due to 
a high thrombophilic risk profile). We have retrospectively divided the population in two groups depending on the use or not of DHCA. The group 1, includes 96 patients operated until 2012, while group 2, 81 consecutive patients from 2012 until 2020. DCHA was adopted in the second era group.

\section{Statistical analysis}

Continuous variables were expressed as mean and standard deviation while categoric variables were expressed as numbers and percentage. Descriptive statistical analysis was performed through chi-square and Student's $t$-test, when appropriate. Operative mortality was defined as death within 30 days of surgery and within the same hospital admission. Survival after surgery was estimated using the life-table and Kaplan-Mayer analysis: differences were tested by the log-rank test. Survival was calculated from the date of surgery. Predictors of mortality were identified by using univariate logistic regression analysis. IBM SPSS Statistics 24 was used for all analyses. Values of $\mathrm{P}<0.05$ were considered significant.

\section{Ethical statement}

The study was conducted in accordance with the Declaration of Helsinki (as revised in 2013) and the Harmonized Tripartite Guideline for Good Clinical Practice from the International Conference on Harmonization. Our institution does not require a review board approval for retrospective studies and informed consent form was waived.

\section{Results}

Of 485 CTEPH patients in our center, 37 do not suffer of $\mathrm{PH}$ being categorized as CTED and none of them undergone PTE or BPA. All cases of CTEPH have been discussed in the dedicated multidisciplinary meeting. Around $56.9 \%$ cases, did not have indication to any kind of re-perfusion therapy, intended as PTE or BPA. Of the remaining CTEPH population, nearly $80 \%$ PTE was indicated and performed. The $63 \%$ of patient reach the operation under specific pulmonary vasodilator therapy. Preoperative population characteristics, echocardiography and hemodynamics are described in Table 1. The most relevant preoperative differences between groups were that in the group 1 , patients were smaller with only $16.7 \%$ of patients with a body mass index more than $30 \mathrm{~kg} / \mathrm{m}^{2}$ respect the $28.8 \%$ in the group $2(\mathrm{P}<0.05)$. In group $1,58.3 \%$ of patients suffered from some degree of associated chronic obstructive pulmonary disease (COPD) while in group 2 only $29.6 \%(\mathrm{P}<0.000)$. Previous acute pulmonary embolism was documented in $44.8 \%$ and $75 \%$ of patients in group 1 and 2 respectively $(\mathrm{P}<0.000)$. Almost $80 \%$ of patients in group 2, reach the operation with some pulmonary vasodilator therapy respect the $56 \%$ of group $1(\mathrm{P}=0.001)$. From a hemodynamic point of view, both groups were comparable, even in the group 1 patients appeared more decompensated, with a higher central venous pressure and a lower right ventricular shortening fraction (RVSF).

As described in the methods, also in group 1, even if trying to avoid DHCA, the surgeon was in implacable necessity to adopt it because inability to perform correctly the PTE. That occurred in more than $50 \%$ of patients $(54.2 \%)$. Also in group 2, while reaching the core temperature of 20 degrees and preparing the cleavage plane, the PTE was feasible to perform without the need of systemic arrest, but that happened only in 4 cases (4.9\%); $60 \%$ of patients required 2 period of DHCA, one for each side, $22.2 \%$ required 3 and only $8 \%$ more than 3 in group 2. Mean time of DHCA was $21 \pm 19$ minutes for all cohort, while was $12 \pm 11$ and $33 \pm 16$ minutes in group 1 and group 2 respectively. Those numbers mirror that probably in group 1, when DHCA was necessarily required, yes it prolonged the cross clamp time, but the arrest was necessary just to detach the very distal part of the fibrotic thrombus. In $7.2 \%$ of cases in group 1 , other cardiac procedures were associated respect 3.7 (excluding the closure of the patent foramen ovalis) $(\mathrm{P}=0.003)$. In group 1 , cross clamp times was 40 minutes longer than group 2. Specific surgical data are represented in Table 2.

Postoperative hemodynamics and outcomes are reported in Table 3. Pulmonary hemodynamics improved equally in both groups reaching a PAPm of $25.2 \pm 6.7 \mathrm{mmHg}$ and PVR of $4.3 \pm 3.0$ Wood units (WU). In $80 \%$ of the cases an immediate reduction of $36 \%$ of the preoperative $\mathrm{PH}$ values was observed, which exceeded $50 \%$ in the 24 successive hours. In $32 \%$ of the cases, a complete normalization of the pulmonary pressure values occurred before invasive monitoring was interrupted, generally in 4th to 5 th postoperative day (POD).

Length of stay in intensive care unit and overall hospitalization were 7.9 and 19 days respectively. Main complication after surgery were, $13.6 \%$ re-thoracotomy for excessive blood loss from drains, pneumonia in $16.4 \%$ of 
Table 1 Preoperative population data

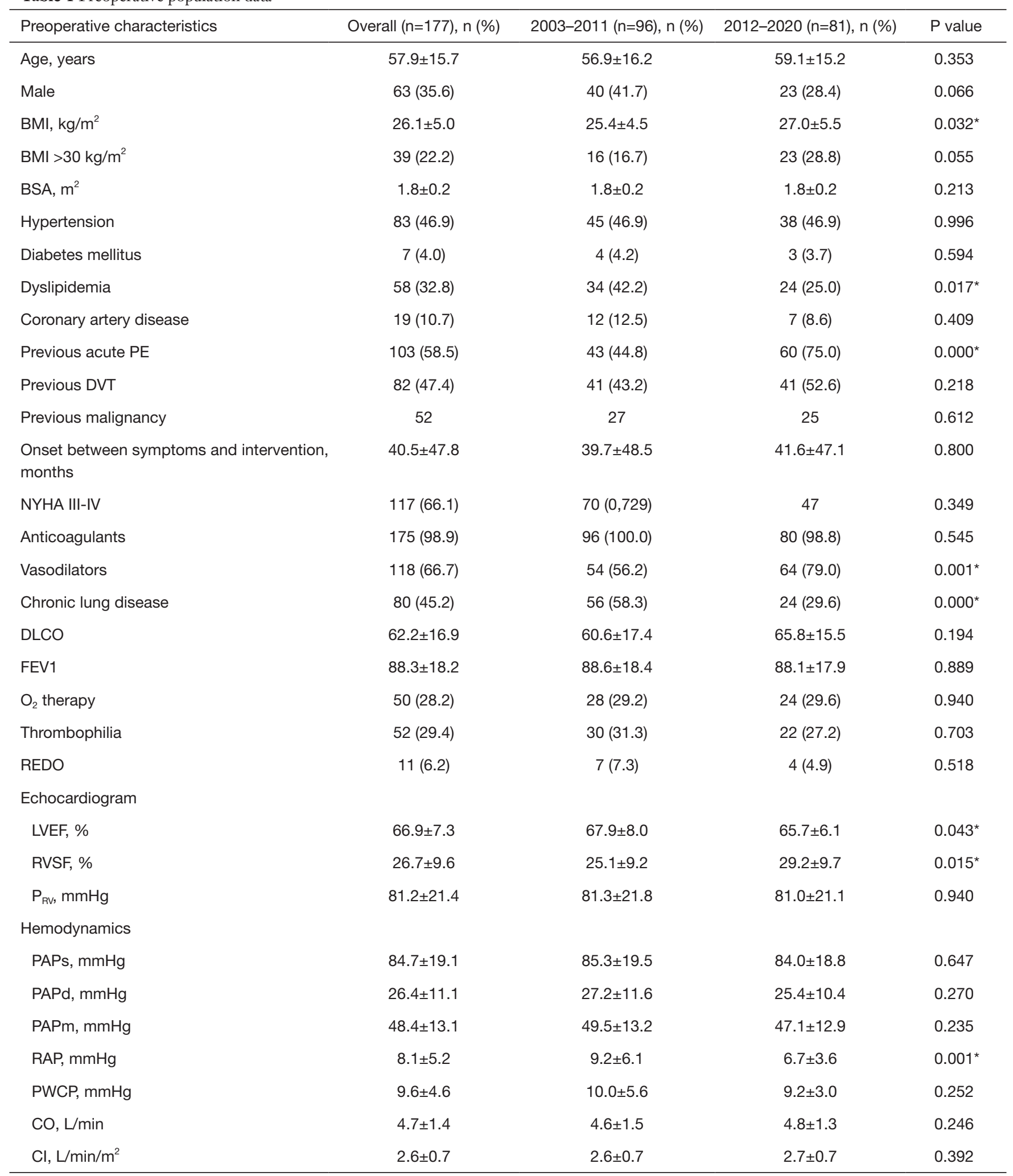

Table 1 (continued) 
Table 1 (continued)

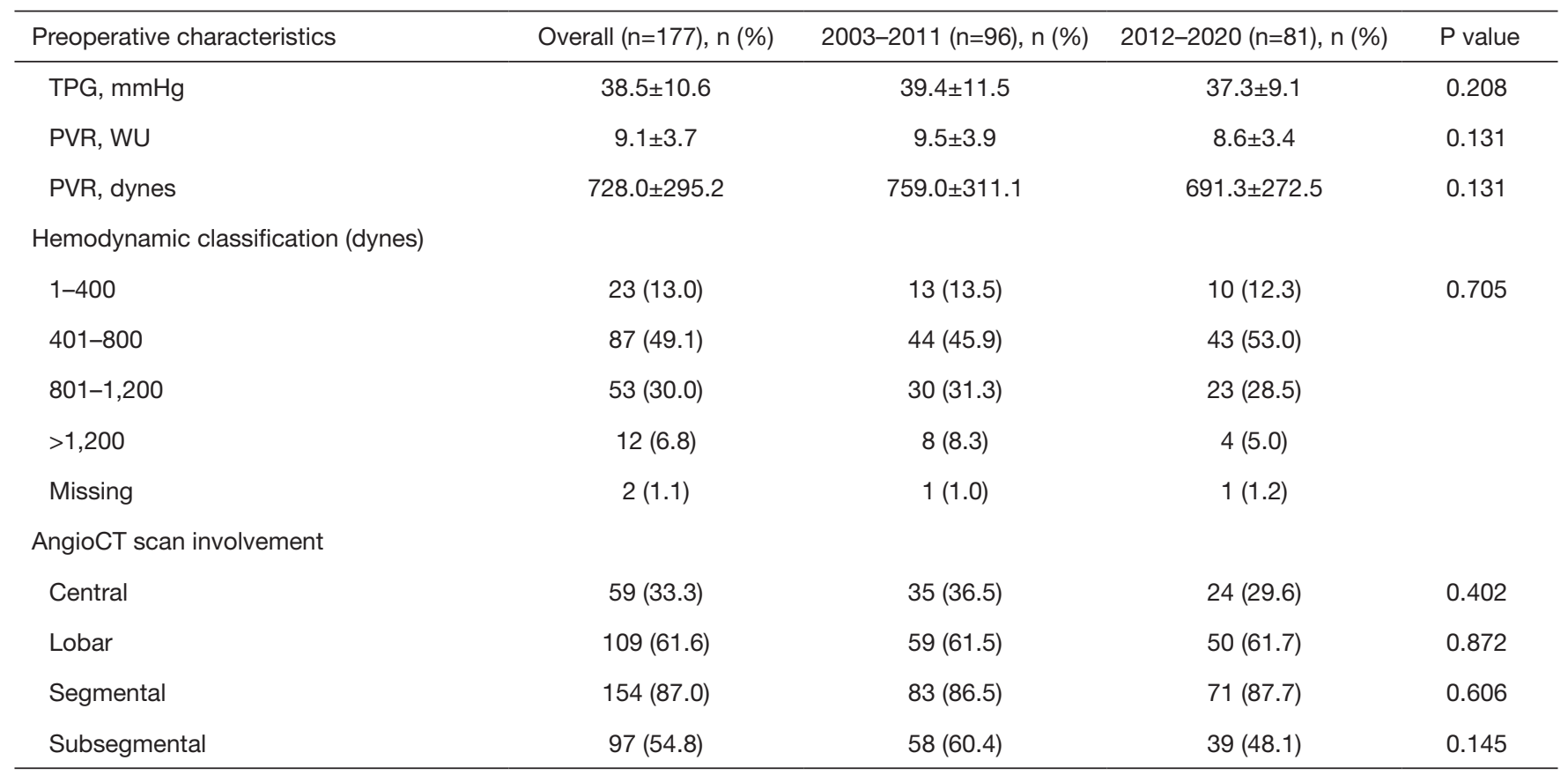

Data are presented as mean \pm standard deviation or number (frequency). * indicates significance $(\mathrm{P}<0.05)$. BMI, body mass index; BSA, body surface area; PE, pulmonary embolism; DVT, deep venous thrombosis; NYHA, New York Heart Association; DLCO, diffusion lung carbonmonoxyde; FEV 1 , forced expiratory volume; LVEF, left ventricle ejection fraction; RVSF, right ventricle systolic function; PRV, right ventricle pressure; PAP, pulmonary artery pressure; RAP, right atrial pressure; PWCP, pulmonary wedge capillary pressure; CO, cardiac output; Cl, cardiac index; TPG, trans pulmonary gradient; PVR, pulmonary vascular resistances; WU, Wood units.

cases, and dialysis in $3.4 \%$ of cases. There were two cases of permanent neurological dysfunction (PND) in group 2: one, a 34 years old female patient, who was operated on cardiac arrest because of massive CTEPH, who suffered from a temporal small ischemic damage causing visus deficit and second one a 78 years old female who had a major brain hemorrhage suddenly after the operation. Overall incidence of PND of 177 cases was $1.1 \%$. Transitory neurological deficit (TND) happened in 8 patients, characterized in 5 of them by choreoathetosis and in the other three cases by transitory confusion. Extra-corporeal membrane oxygenator (ECMO) was required in 22 patients (12.4\%) lasting an average of $10.3 \pm 7.9$ days. Even without statistically significance, ECMO was implanted in $15.6 \%$ of patient in group 1 while only in $8.6 \%$ in group 2 . ECMO was mainly implanted by a peripheral approach and dominant indication was residual over systemic $\mathrm{PH}$ and/ or right ventricular failure. Mortality in ECMO was $50 \%$. Successful Weaning from ECMO was feasible in the $46.5 \%$ and $57.1 \%$ of patients in group 1 and 2 respectively. Of the eleven weaned patients, 3 subsequently died because septic shock, multiorgan failure and cardiorespiratory failure; $72 \%$ of weaned patient survived. Specifically, in group 1, ECMO was needed exactly in $16.6 \%$ of cases where DHCA was avoided (8/48) respect $10.9 \%$ in those operated on DHCA (14/128). More data about ECMO after PEA, and our management policy can be found in a recent published article, based on 154 PTE cases (9).

Operative mortality was 10.2 being $15.6 \%$ and $3.7 \%$ from the groups 1 and 2. Univariate inference demonstrated as risk factors for operative mortality, being part of group 1, high PVR values, worst preoperative functional class, associated COPD, higher CVP and longer operation time. Risk factors for ECMO at the univariate analysis are almost the same, except the era, while the cross clamp time represents a higher risk of ECMO. Univariate analysis is reported in Table 4.

Mean follow up time was $66.7 \pm 42.2$ months. The longterm survival represented in the Kaplan Mayer curves (Figure 2) demonstrated a significant difference (Log rank $=0.008$ ) between groups, mostly due to the higher mortality in group 1 . Nearly $93 \%$ of PTE patient are free of specific 
Table 2 Intraoperative data

\begin{tabular}{|c|c|c|c|c|}
\hline Intraoperative characteristics & Overall (n=177), n (\%) & 2003-2011 (n=96), n (\%) & 2012-2020 (n=81), n (\%) & $P$ value \\
\hline CPB time, $\min$ & $284 \pm 67$ & $291 \pm 77$ & $275 \pm 59$ & 0.131 \\
\hline DHCA & $128(72.3)$ & $52(54.2)$ & $76(93.8)$ & $0.000^{*}$ \\
\hline Total DHCA time, min & $21 \pm 19$ & $12 \pm 17$ & $33 \pm 16$ & $0.000^{*}$ \\
\hline 0 & $48(27.1)$ & $44(45.8)$ & $4(4.9)$ & \\
\hline 1 & $37(20.9)$ & 32 (33.3) & $5(6.2)$ & \\
\hline 2 & $58(32.8)$ & $11(11.4)$ & $47(58.0)$ & \\
\hline 3 & $25(14.1)$ & $7(7.3)$ & $18(22.2)$ & \\
\hline Septal defects & $38(21.5)$ & $28(29.2)$ & $10(12.3)$ & \\
\hline CABG & $6(3.4)$ & $3(3.1)$ & $3(3.7)$ & \\
\hline Valvular & $3(1.7)$ & $3(3.1)$ & $0(-)$ & \\
\hline Other & $1(0.5)$ & $1(1.0)$ & $0(-)$ & \\
\hline
\end{tabular}

* indicates significance $(\mathrm{P}<0.05)$. X-clamp time, aortic cross clamp time; CPB, cardiopulmonary bypass; DHCA, deep hypothermic circulatory arrest; CABG, coronary artery bypass.

pulmonary vasodilator drugs and $66 \%$ had normalization of $\mathrm{PH}$ values. A total of 5 patients, required balloon angioplasty in the follow-up. None of our patients died in the follow up because of cardiac failure secondary to CTEPH. Four patients required PTE reintervention after PEA, one 46 years old lady, who underwent second PTE 4 years after first PTE performed elsewhere with very high $\mathrm{PH}$, who need postoperative ECMO, weaned and treated with $\mathrm{BPA}$ because of residual $\mathrm{PH}$; three other patients $(1.7 \%$ of recurrence) were operated the first time in our center, and after 4, 6 and 5 years each, they require a second PTE. All of them had lupus anticoagulant syndrome.

\section{Discussion}

We have retrospectively presented 17 years of experience in pulmonary thromboendarterectomy performed in 174 patients for a total of 177 procedures. At the beginning of our experience in 2002/2003, and despite having attended the most expert center in the world and founder of PTE, that is the center of Prof. Jamieson in San Diego (10), we adopted an alternative technique to that traditionally accepted by all experts. Technique based on a different management of the $\mathrm{CPB}$ avoiding deep hypothermia and arrest of the circulation (DHCA), in line with our policy in aortic arch surgery based on the use of moderate hypothermia at $25^{\circ} \mathrm{C}$, given the widely reported neurological and coagulation complications related to use of DHCA (11).

Our technique involved the conventional PTE operation, but reducing the flow of extracorporeal circulation to the minimum one, necessary to maintain good tissue perfusion values and with minimal retrograde flow, allowing a complete pulmonary endarterectomy to be performed perfectly.

As previously described, the results in terms of improvement and resolution of the $\mathrm{PH}$ values were satisfactory, but frequently, it was indispensable to appeal to DHCA while on myocardial cardioplegic arrest, significantly increasing the times of $\mathrm{CPB}$ and aortic clamping. For this reason, since 2012, thanks also to the advice and guidelines of the main expert task forces (12), we have routinely adopted the DHCA.

We have then compared the two cohorts (group 1, 
Table 3 Postoperative data

\begin{tabular}{|c|c|c|c|c|}
\hline Early outcomes & Overall (n=177), n (\%) & 2003-2011 (n=96), n (\%) & 2012-2020 (n=81), n (\%) & $P$ value \\
\hline PAPs, mmHg & $39.4 \pm 11.8$ & $39.9 \pm 11.4$ & $38.8 \pm 12.3$ & 0.543 \\
\hline $\mathrm{PAPd}, \mathrm{mmHg}$ & $17.5 \pm 6.2$ & $18.0 \pm 6.4$ & $16.8 \pm 5.9$ & 0.200 \\
\hline PAPm, mmHg & $25.2 \pm 6.7$ & $25.3 \pm 6.6$ & $24.8 \pm 6.8$ & 0.639 \\
\hline TPG, mmHg & $16.2 \pm 6.6$ & $16.4 \pm 6.3$ & $15.9 \pm 7.2$ & 0.700 \\
\hline PVR, UW & $4.2 \pm 2.7$ & $4.3 \pm 3.0$ & $3.9 \pm 2.0$ & 0.575 \\
\hline $\mathrm{CO}, \mathrm{L} / \mathrm{min}$ & $4.5 \pm 1.4$ & $4.5 \pm 1.4$ & $4.4 \pm 1.4$ & 0.663 \\
\hline $\mathrm{Cl}, \mathrm{L} / \mathrm{min} / \mathrm{m}^{2}$ & $2.7 \pm 0.9$ & $2.9 \pm 1.0$ & $2.5 \pm 0.6$ & $0.005^{*}$ \\
\hline Ventilation, hours & $75.8 \pm 162.8$ & $88.3 \pm 190.1$ & $58.3 \pm 113.5$ & 0.208 \\
\hline Drainage loss within $48 \mathrm{~h}, \mathrm{~mL}$ & $893.1 \pm 673.5$ & $984.5 \pm 808.0$ & $769.6 \pm 403.4$ & $0.026^{*}$ \\
\hline Re-thoracotomy for bleeding & $24(13.6)$ & $13(13.4)$ & $11(13.5)$ & 0.964 \\
\hline Permanent dialysis & $6(3.4)$ & $2(2.0)$ & $4(4.9)$ & 0.269 \\
\hline Pneumonia & $29(16.4)$ & $16(16.6)$ & $13(16.0)$ & 0.888 \\
\hline Sepsis & $13(7.3)$ & $9(9.3)$ & $4(4.9)$ & 0.252 \\
\hline Tracheostomy & $10(5.6)$ & $6(6.3)$ & $4(4.9)$ & 0.477 \\
\hline PND & $2(1.1)$ & $0(-)$ & $2(2.5)$ & 0.210 \\
\hline Veno-arterial & $21(11.8)$ & $15(15.6)$ & $6(7.4)$ & 0.318 \\
\hline Veno-venous & $1(0.5)$ & $0(-)$ & $1(1.2)$ & \\
\hline Time on ECMO, days & $10.3 \pm 7.9$ & $11.5 \pm 7.9$ & $7.7 \pm 7.9$ & 0.303 \\
\hline Successful weaning & $11(50.0)$ & $7(46.6)$ & $4(57.1)$ & 0.367 \\
\hline In-hospital death & $18(10.2)$ & $15(15.6)$ & $3(3.7)$ & $0.009^{*}$ \\
\hline \multicolumn{5}{|l|}{ Echocardiogram at discharge } \\
\hline LVEF & $65.2 \pm 6.4$ & $66.6 \pm 7.5$ & $64.0 \pm 5.0$ & $0.015^{*}$ \\
\hline RVSF & $35.2 \pm 9.5$ & $36.5 \pm 8.5$ & $34.1 \pm 10.2$ & 0.174 \\
\hline $\mathrm{P}_{\mathrm{RV}}$ & $42.5 \pm 17.3$ & $44.0 \pm 17.2$ & $41.1 \pm 17.3$ & 0.383 \\
\hline
\end{tabular}

Data are presented as mean \pm standard deviation or number (frequency). * indicates significance $(\mathrm{P}<0.05)$. PAP, pulmonary artery pressure; RAP, right atrial pressure; CO, cardiac output; Cl, cardiac index; TPG, trans pulmonary gradient; PVR, pulmonary vascular resistances; ICU, intensive care unit; PND, permanent neurological deficit; ECMO, extracorporeal membrane oxygenation; LVEF, left ventricle ejection fraction; RVSF, right ventricle systolic function; $\mathrm{PRV}_{\mathrm{RV}}$ right ventricle pressure. 
Table 4 Univariate risk factors analysis for in-hospital mortality and for postoperative ECMO

\begin{tabular}{|c|c|c|c|c|c|c|}
\hline \multirow[t]{2}{*}{ Risk factor analysis } & \multicolumn{3}{|c|}{$\begin{array}{l}\text { Logistic regression for in-hospital mortality; } \\
\text { univariable analysis }\end{array}$} & \multicolumn{3}{|c|}{$\begin{array}{l}\text { Logistic regression for ECMO; } \\
\text { univariable analysis }\end{array}$} \\
\hline & $P$ value & OR & $95 \% \mathrm{Cl}$ & $P$ value & OR & $95 \% \mathrm{Cl}$ \\
\hline Age, years & 0.841 & 0.997 & $0.97-1.03$ & 0.178 & 0.982 & $0.96-1.01$ \\
\hline Previous PE & 0.441 & 0.681 & $0.26-1.81$ & 0.388 & 0.674 & $0.28-1.65$ \\
\hline NYHA III-IV & $0.042^{*}$ & 8.330 & $1.07-64.42$ & $0.044^{*}$ & 4.653 & $1.04-20.80$ \\
\hline Preoperative vasodilators & 0.522 & 0.720 & $0.26-1.97$ & 0.654 & 0.808 & $0.32-2.05$ \\
\hline $\mathrm{FEV}_{1}$ & 0.057 & 0.972 & $0.94-1.00$ & $0.005^{\star}$ & 0.959 & $0.93-0.98$ \\
\hline $\mathrm{O}_{2}$ therapy & $0.008^{*}$ & 4.071 & $1.45-11.41$ & $0.016^{\star}$ & 3.131 & $1.23-7.94$ \\
\hline Thrombophilia & 0.201 & 0.433 & $0.12-1.56$ & 0.425 & 0.651 & $0.22-1.87$ \\
\hline \multicolumn{7}{|l|}{ Echocardiogram } \\
\hline LVEF, \% & 0.872 & 1.003 & $0.94-1.08$ & 0.479 & 0.977 & $0.91-1.04$ \\
\hline RVSF, \% & 0.090 & 0.943 & $0.88-1.01$ & 0.494 & 0.980 & $0.92-1.04$ \\
\hline $\mathrm{P}_{\mathrm{RV}}, \mathrm{mmHg}$ & 0.109 & 1.020 & $0.99-1.04$ & 0.059 & 1.023 & $0.99-1.05$ \\
\hline $\mathrm{RAP}, \mathrm{mmHg}$ & $0.002^{*}$ & 1.158 & $1.05-1.27$ & 0.097 & 1.063 & $0.99-1.14$ \\
\hline PWCP, mmHg & 0.552 & 0.960 & $0.83-1.10$ & 0.518 & 0.959 & $0.84-1.09$ \\
\hline $\mathrm{CO}, \mathrm{L} / \mathrm{min}$ & $0.010^{*}$ & 0.490 & $0.29-0.84$ & $0.026^{\star}$ & 0.586 & $0.37-0.94$ \\
\hline $\mathrm{Cl}, \mathrm{L} / \mathrm{min} / \mathrm{m}^{2}$ & 0.211 & 0.584 & $0.25-1.36$ & 0.282 & 0.662 & $0.31-1.40$ \\
\hline TPG, mmHg & 0.916 & 0.997 & $0.95-1.05$ & 0.384 & 1.020 & $0.98-1.07$ \\
\hline RVP, UW & $0.032^{*}$ & 1.149 & $1.01-1.31$ & $0.038^{\star}$ & 1.135 & $1.01-1.28$ \\
\hline Hemodinamic classification & $0.017^{*}$ & 2.177 & $1.15-4.12$ & $0.047^{\star}$ & 1.819 & $1.01-3.28$ \\
\hline \multicolumn{7}{|l|}{ AngioCT scan involvement } \\
\hline Central & 0.139 & 2.100 & $0.79-5.61$ & 0.369 & 1.530 & $0.60-3.87$ \\
\hline Lobar & 0.170 & 2.247 & $0.70-7.15$ & 0.567 & 1.322 & $0.51-3.44$ \\
\hline Segmental & 0.957 & 1.043 & $0.22-4.92$ & 0.737 & 0.798 & $0.21-2.98$ \\
\hline Subsegmental & 0.342 & 1.647 & $0.59-4.61$ & 0.566 & 1.315 & $0.51-3.36$ \\
\hline
\end{tabular}

Table 4 (continued) 
Table 4 (continued)

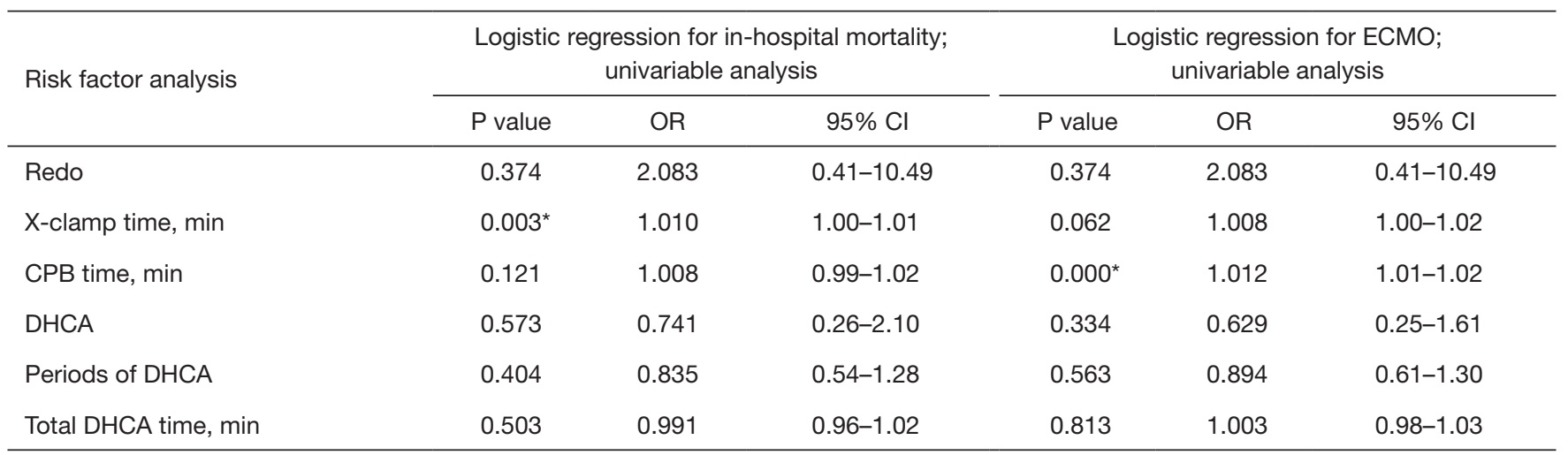

* indicates significance $(\mathrm{P}<0.05)$. ECMO, extracorporeal membrane oxygenation; BMI, body mass index; PE, pulmonary embolism; NYHA, New York Heart Association; DLCO, diffusion lung carbonmonoxyde; FEV ${ }_{1}$, forced expiratory volume; LVEF, left ventricle ejection fraction; RVSF, right ventricle systolic function; PRv, right ventricle pressure; PAP, pulmonary artery pressure; RAP, right atrial pressure; PWCP, pulmonary wedge capillary pressure; $\mathrm{CO}$, cardiac output; $\mathrm{Cl}$, cardiac index; TPG, trans pulmonary gradient; PVR, pulmonary vascular resistances; X-clamp time, aortic cross clamp time; CPB,cardiopulmonary bypass; DHCA, deep hypothermic circulatory arrest.

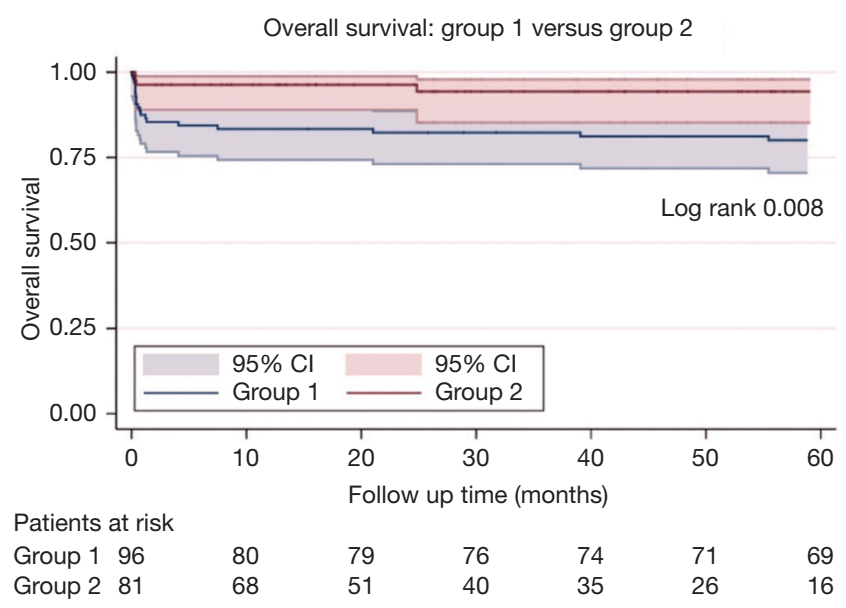

Figure 2 Kaplan-Mayer overall survival analysis.

consisting of 96 patients operated in the first 9 years and group 2 with 81 patients operated in the following 8 years) the most significant figure is represented by the reduction in operative mortality. The two groups have similar demographic and preoperative characteristics, although in group 1, the patients were more decompensated, with greater impairment of lung function and thus also of the function of the right ventricle in terms of fraction of shortening and right atrial pressure.

In terms of complications after the operation, drain's loss and incidence of re-thoracotomy was higher in group one. Length of intubation was also similar. Neurological events, particularly those transient and then reversible were slightly higher in the group 2, characterize mainly by chorea and disorientation. Also renal insufficiency requiring dialysis was also higher in this group, without significance. Further analysis would be required to analyze this finding.

Inexorably, differences in CPB management led to a significant reduction in the duration of extracorporeal circulation and aortic clamping in group 2 despite the systematic adoption of DHCA.

Need of ECMO after the operation was similar in both groups, but weaning and survival improved in the second group.

Previously, we have also analyzed the different hemodynamic profiles of our population, to identify those most at risk or not (9). As previously reported by the Canadian group, dysfunction of the right ventricle represents a risk factor for mortality (13) while the degree of PH affects the hemodynamic result after PTE: patients with PVR values greater than 1,200 dynes.sec. $\mathrm{cm}^{-5}$ are more likely to have residual $\mathrm{PH}$ although improved. The combination of high $\mathrm{PH}$ together with right ventricular dysfunction, might result in high risk of operative mortality and in these cases, associated pathologies, age, general status and expectations must be accurately weighted.

There are patients who often need targeted therapy for PH or even can take advantage of BPA after the PTE operation during the follow up. At this point the BPA can be interpreted as an additional therapeutic weapon synergistic to surgical treatment $(14,15)$. 
There is an important factor that influences preoperative differences and then results in between groups, which in not only our selection capability. The other reason is that, since 2015 another therapeutic tool for CTEPH patient is available in our center. This is the BPA. During the second era from 2012 to 2020, for more than half of the second period, in cases where the pathology was excessively distal or the characteristics of the patient prohibitive for a PTE intervention, we had this therapeutic alternative. Many of these patients would have undergone PTE surgery in the first period given the unavailability of BPA, explaining the pre and postoperative differences of group 1 compared to group 2.

Regarding the percentage of our global population of CTEPH candidates and subjected to PTE intervention it is necessary to report as previously described, that a significant number of patients were not candidates for any type of therapy except pharmacological, due to limited anatomical involvement with low hemodynamic repercussions or patients affected by other pathologies with greater clinical and prognostic impact. Of the other CTEPH patients, the acceptability rate for PTE is approximately $80 \%$.

Another controversial topic is the use of preoperative specific vasodilators in patients with indication to PTE. We almost routinely perform PTE on patients with this therapy, mainly oral 5 -phosphodiesterase inhibitors. We did not find technical difficulties. Patients reach operation with slightly better pulmonary hemodynamics, and consequently better right ventricular functions, which have been demonstrated to impact outcomes. Furthermore, the medication before the operation serves as a drug test, eliminating in some manner the healthy vessels vasoconstriction contribution to the $\mathrm{PH}$, adding degree of reversibility information.

\section{Conclusions}

The present work has many limitation due to its retrospective nature. Our population is very heterogeneous and we aware that many other and not analysed factor might influence results. However and in conclusion, our results demonstrate without any doubt that, in a dedicated center, with precise implementation protocols throughout the diagnostic and therapeutic path of a considered a rare pathology as CTEPH, they are perfectly in line with the results of centers with greater number of annual procedures. We fully agree that an expert center like ours must be able to offer the patient with CTEPH, all therapeutic possibilities and a well-defined diagnostic path and a dedicated team regardless of the degree and severity of the pathology. Still, PTE surgery must be the first therapeutic choice in patients with CTEPH, with involvement of at least the segmental pulmonary branches, in the absence of major contraindications to the intervention.

\section{Acknowledgments}

Funding: None.

\section{Footnote}

Provenance and Peer Review: This article was commissioned by the Guest Editors (Andrea Dell'Amore and Nizar Asadi) for the series "Mechanical Extracorporeal CardioRespiratory Supports in General Thoracic Surgery" published in Current Challenges in Thoracic Surgery. The article has undergone external peer review.

Reporting Checklist: The authors have completed the STROBE reporting checklist. Available at https://ccts. amegroups.com/article/view/10.21037/ccts-20-137/rc

Data Sharing Statement: Available at https://ccts.amegroups. com/article/view/10.21037/ccts-20-137/dss

Conflicts of Interest: The authors have completed the ICMJE uniform disclosure form (available at https://ccts. amegroups.com/article/view/10.21037/ccts-20-137/coif). The series "Mechanical Extracorporeal Cardio-Respiratory Supports in General Thoracic Surgery" was commissioned by the editorial office without any funding or sponsorship. The authors have no other conflicts of interest to declare.

Ethical Statement: The authors are accountable for all aspects of the work in ensuring that questions related to the accuracy or integrity of any part of the work are appropriately investigated and resolved. The study was conducted in accordance with the Declaration of Helsinki (as revised in 2013) and the Harmonized Tripartite Guideline for Good Clinical Practice from the International Conference on Harmonization. The study does not require institutional ethics board approval and individual consent for this retrospective analysis was waived.

Open Access Statement: This is an Open Access article distributed in accordance with the Creative Commons Attribution-NonCommercial-NoDerivs 4.0 International 
License (CC BY-NC-ND 4.0), which permits the noncommercial replication and distribution of the article with the strict proviso that no changes or edits are made and the original work is properly cited (including links to both the formal publication through the relevant DOI and the license). See: https://creativecommons.org/licenses/by-nc-nd/4.0/.

\section{References}

1. Lang IM, Madani M. Update on chronic thromboembolic pulmonary hypertension. Circulation 2014;130:508-18.

2. Moser KM, Bloor CM. Pulmonary vascular lesions occurring in patients with chronic major vessel thromboembolic pulmonary hypertension. Chest 1993;103:685-92.

3. Simonneau G, Torbicki A, Dorfmüller P, et al. The pathophysiology of chronic thromboembolic pulmonary hypertension. Eur Respir Rev 2017;26:160112.

4. Jenkins D, Madani M, Fadel E, et al. Pulmonary endarterectomy in the management of chronic thromboembolic pulmonary hypertension. Eur Respir Rev 2017;26:160111.

5. Savini C, Murana G, Di Eusanio M, et al. Safety of singledose histidine-tryptophan-ketoglutarate cardioplegia during minimally invasive mitral valve surgery. Innovations (Phila) 2014;9:416-20.

6. Mikus PM, Mikus E, Martìn-Suàrez S, et al. Pulmonary endarterectomy: an alternative to circulatory arrest and deep hypothermia: mid-term results. Eur J Cardiothorac Surg 2008;34:159-63.

7. Mikus PM, Dell'Amore A, Pastore S, et al. Pulmonary endarterectomy: is there an alternative to profound hypothermia with cardiocirculatory arrest? Eur J Cardiothorac Surg 2006;30:563-5.

doi: $10.21037 /$ ccts-20-137

Cite this article as: Martin-Suarez S, Gliozzi G, Loforte A, Niro F, Fiorentino M, Cavalli GG, Palazzini M, Saia F, Barbera N, La Monaca M, Galiè N, Pacini D. Pulmonary thromboendarterectomy for chronic thromboembolic pulmonary artery hypertension. Curr Chall Thorac Surg 2021;3:13.
8. Vuylsteke A, Sharples L, Charman G, et al. Circulatory arrest versus cerebral perfusion during pulmonary endarterectomy surgery (PEACOG): a randomised controlled trial. Lancet 2011;378:1379-87.

9. Martin-Suarez S, Gliozzi G, Fiorentino M, et al. Role and management of extracorporeal life support after surgery of chronic thromboembolic pulmonary hypertension. Ann Cardiothorac Surg 2019;8:84-92.

10. Jamieson SW, Kapelanski DP, Sakakibara N, et al. Pulmonary endarterectomy: experience and lessons learned in 1,500 cases. Ann Thorac Surg 2003;76:1457-62; discussion 1462-4.

11. Pacini D, Leone A, Di Marco L, et al. Antegrade selective cerebral perfusion in thoracic aorta surgery: safety of moderate hypothermia. Eur J Cardiothorac Surg 2007;31:618-22.

12. Mayer E, Jenkins D, Lindner J, et al. Surgical management and outcome of patients with chronic thromboembolic pulmonary hypertension: results from an international prospective registry. J Thorac Cardiovasc Surg 2011;141:702-10.

13. de Perrot M, Thenganatt J, McRae K, et al. Pulmonary endarterectomy in severe chronic thromboembolic pulmonary hypertension. J Heart Lung Transplant 2015;34:369-75.

14. Wiedenroth CB, Liebetrau C, Breithecker A, et al. Combined pulmonary endarterectomy and balloon pulmonary angioplasty in patients with chronic thromboembolic pulmonary hypertension. J Heart Lung Transplant 2016;35:591-6.

15. Shimura N, Kataoka M, Inami T, et al. Additional percutaneous transluminal pulmonary angioplasty for residual or recurrent pulmonary hypertension after pulmonary endarterectomy. Int J Cardiol 2015;183:138-42. 